(C)2005 IEEE. Personal use of this material is permitted. However, permission to reprint/republish this material for advertising or promotional purposes or for creating new collective works for resale or redistribution to servers or lists, or to reuse any copyrighted component of this work in other works must be obtained from the IEEE. 


\section{A Single Cell Maximum Power Point Tracking Converter without a Current Sensor for High Performance Vehicle Solar Arrays}

\author{
P.J.Wolfs \\ Central Queensland University \\ Rockhampton Mail Center QLD 4702, Australia
}

\author{
L.Tang \\ Oak Ridge National Laboratory \\ Knoxville TN 37932, USA.
}

\begin{abstract}
A maximum power tracker is developed for a single high performance GaAs solar cell to reduce the impact of variations in cell illumination for highly curved arrays as required for vehicle applications. This solution also finds applications in concentrating photovoltaic systems where the incident energy may vary due to optical imperfections. On a curved array, each cell has a directly connected tracker that operates autonomously. An examination of the switching ripple performance of a large number of series connected asynchronous converters is made. The tracker uses a highly efficient $600 \mathrm{~mW}$ buck converter operating at $20 \mathrm{kHz}$ with a synchronous rectifier. A dedicated MSP340 processor is capable of the total converter control task. Operating at $\mathbf{1 . 8 \mathrm { V }}$ the controller can be directly powered by the cell. A charge pump is used to develop gate drive voltages for the converter MOSFETs. A maximum power tracking algorithm based on observations of cell voltage and converter duty cycle is demonstrated. The load power may be maximized by maximizing the converter average output voltage. An interior voltage loop is used to control cell voltage and assists in securing a $1.5 \mathrm{mS}$ response to illumination changes.
\end{abstract}

\section{INTRODUCTION}

Hybrid and electric vehicles can significantly benefit from the inclusion of photovoltaic arrays, [1,2]. As the area available is small, perhaps a couple of square metres, high efficiency cells are preferred. Dual and triple junction mono-crystalline cells achieve conversion efficiencies beyond $28 \%,[3,4]$.

Vehicles require curved surfaces to achieve low aerodynamic drag. Array curvature combines with rapid illumination changes due to shading by road-side vegetation and structures to present significant challenges for the power management of solar arrays. Shadows can cross vehicle arrays at $20 \mathrm{~ms}^{-1}$ and individual cells will shadow in a few milliseconds.

Maximum power point trackers, (MPPT), are normally provided for large numbers of interconnected cells. Some attempts have been made to provide maximum power tracking for relatively small numbers of cells with maximum power trackers being proposed at the module level, [5]. In this cases power tracking is provided to a group of a few dozen cells with a total power of some tens of watts. Even at this level care needs to be taken to limit the amount of power required for the converter controls and to restrict the

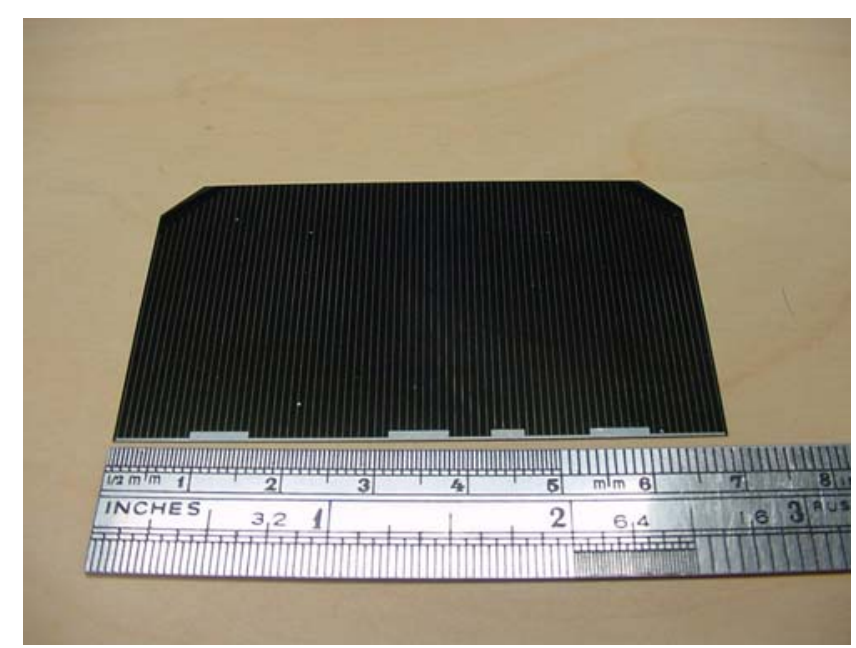

Figure 1: A Dual Junction Gallium Arsenide Cell, [4].

converter losses. A major challenge for the application of MPPTs to small numbers of cells is the need to develop low cost, low power control devices and small converters with high efficiencies at power levels of a few watts or even at a fraction of a watt.

This paper demonstrates that recent advances in electronics, especially in devices intended for the low power consumer market, makes possible maximum power tracking devices that are distributed at the single cell level where the total power processed may be less than one watt.

\section{POWER CONVERTER DESIGN}

Dual and triple junction Gallium Arsenide cells have room temperature maximum power point voltages of approximately 2.0 and $2.5 \mathrm{~V},[3,4]$. For applications such as vehicles where space is at a premium, these cells can achieve efficiencies up to $28 \%$ by matching several vertically stacked junctions to extract the most energy across the wavelengths of the solar spectrum. As a consequence of the series connections of the junctions, the cell voltages are relatively high. A dual junction cell, shown in Figure 1, with a nominal current of $300 \mathrm{~mA}$ yields a maximum power of $600 \mathrm{~mW}$ and will be the focus of this paper. The characteristics of the cell are shown as Figure 2. 
A range of DC-DC converter topologies could be applied to the maximum power tracking task. Choices include:

- A direct converter, either buck or boost, that processes the entire cell output power to produce either a voltage or current compliant output allowing many cells and converters to be series or parallel connected;

- A direct converter, with voltage inversion, that allows series connected strings of cells to transfer energy between adjacent cells to achieve a maximum power point for each individual cell, [6];

- Bypassing current away from shadowed or underperforming cells using an isolated converter and transferring that energy to the output of the array, [7].

A buck topology was selected allowing multiple cells, and their individual converters to be series connected. A significant advantage is the buck converter inductors are all effectively series connected and can be replaced by a single device yielding an inductorless converter package at the cell level. The other approaches do not yield this advantage.

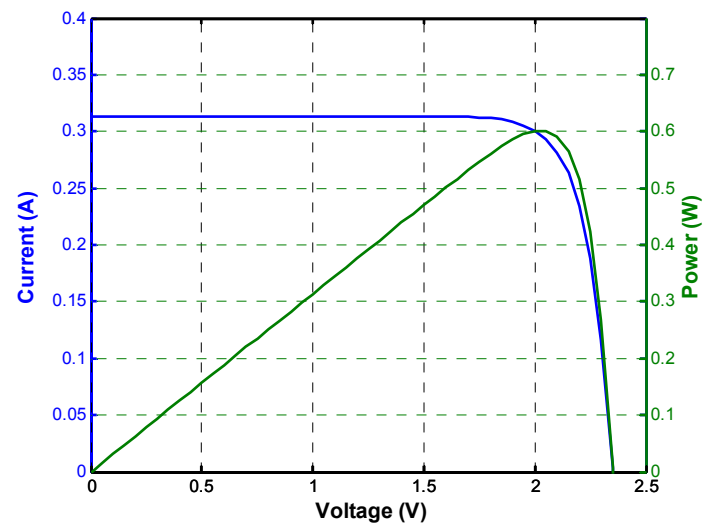

Figure 2: The $i-v$ and $p-v$ characteristics of the dual junction cells at $28^{\circ}$ and $1000 \mathrm{~W} / \mathrm{m} 2$

The converter schematic is shown as Figure 3. Terminals $\mathrm{X}$ and $\mathrm{Y}$ are the load terminals. The major control element is an ultra-low power Texas Instruments MSP430 microprocessor which is capable of operation from a $1.8 \mathrm{~V}$ supply with a current demand of a few hundred microamps. This device performs duty cycle modulation and the maximum power tracking function using the cell voltage and the converter duty cycle to infer cell power. The switches of the buck converter and synchronous rectifier are surface mount MOSFETs selected for a combination of:

- Low gate threshold voltages;

- Low on-state resistance;

- Low gate charge.

The MOSFETs are directly driven by a TLC3702 comparator. This comparator has a $5 \mathrm{~V}$ power supply from a charge pump circuit formed by diodes $D_{1}$ to $D_{4}$ and their associated capacitors. A feature of this arrangement is that the gate source voltage for the top MOSFET $\mathrm{Q}_{1}$ is reduced by the elevation in the source voltage at turn on. The resulting $\mathrm{R}_{\mathrm{dson}}$ for the top device is higher than the lower device and this is normally used as the synchronous rectifier. Dead time is a significant loss issue. During the dead time the load current flows in the inverse diodes and these have a far higher forward drop than the MOSFETs themselves. This is the largest loss mechanism.

Gate charge is very important as the gate current must be sourced by a voltage multiplier and this generates more loss than the device conduction losses. Dead time losses and gate charge losses manifest themselves as a loss component proportional to frequency. They are much more significant than the actual switch losses. Capacitor $\mathrm{C}_{1}$ is a $100 \mu \mathrm{F} 6.3 \mathrm{~V}$ ceramic chip capacitor, ESR must be as small as possible to avoid high losses.

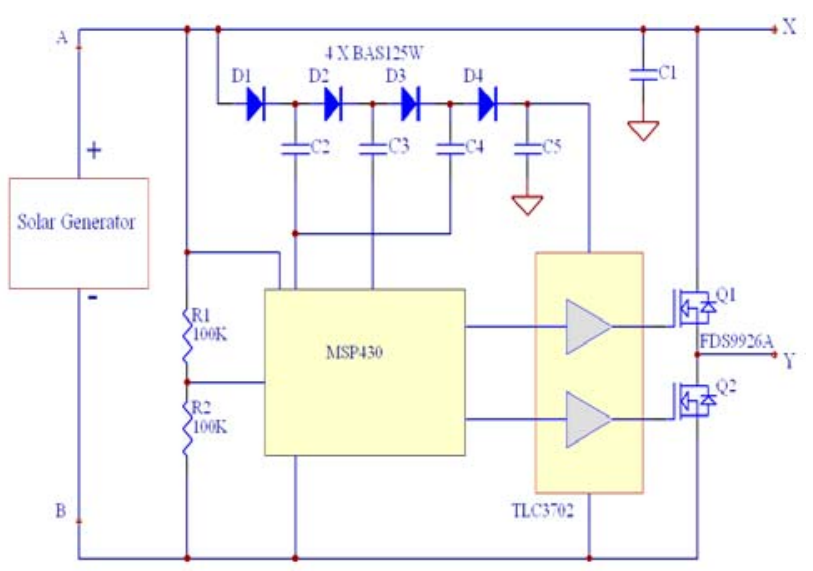

Figure 3: Single cell MPPT converter.

Table I shows the different estimated losses in this converter, namely the loss during dead-time due to inverse diode conduction, $\mathrm{P}_{\text {dead }}$, the MOSFET conduction loss, $\mathrm{P}_{\text {on }}$, the gate charge loss, $\mathrm{P}_{\text {gate }}$, switching loss, $\mathrm{P}_{\text {switching }}$ and total loss at different switching frequencies.

\section{MULTIPLE CELL OPERATION}

A vehicle array will consist of several hundred cells arranged in series strings of 20 to (potentially) in excess of 200 cells. While it may be possible to synchronise the switching operations in many cells to achieve switching frequency elimination, this paper focuses on asynchronously switching cells. In order to secure high efficiency in the cell converters switching frequencies below $20 \mathrm{kHz}$ are desired. Gate charge losses are more significant than switching loss. Some asynchronous strategies can maximize efficiency by tailoring the switching strategy to optimize total converter losses.

The output voltage of large number of asynchronously switching series connected buck converters will follow a binomial distribution. The average output voltage of the group of $\mathrm{n}$ cells, with an input voltage $\mathrm{V}_{\text {in }}$ and a duty cycle 
$\mathrm{d}$, increases linearly with $\mathrm{n}$ while the switching ripple or the distortion voltage, $\mathrm{V}_{\text {dist }}$, rises as $\sqrt{n}$.

$$
v_{\text {dist }}=v_{\text {in }} \sqrt{n\left(d-d^{2}\right)}
$$

Likewise the average volt second area, A, for a shared filter inductor follows an $\sqrt{n}$ relationship.

$$
A=\sqrt{n} \frac{\mathcal{V}_{\text {in }}}{f}\left(d-d^{2}\right)
$$

TABLE I.

MAJOR POWER LOSS ESTIMATES FOR THE CONVERTER $(\mathrm{mW})$

\begin{tabular}{|c|c|c|c|}
\hline & $\mathbf{2 0 k H z}$ & $\mathbf{1 0} \mathbf{~} \mathbf{H z}$ & $\mathbf{2} \mathbf{~ k H z}$ \\
\hline $\mathbf{P}_{\text {dead }}$ & 14.4 & 7.2 & 1.4 \\
\hline $\mathbf{P}_{\text {on }}$ & 10.8 & 10.8 & 10.8 \\
\hline $\mathbf{P}_{\text {gate }}$ & 1.8 & 0.9 & 0.2 \\
\hline $\mathbf{P}_{\text {switching }}$ & 0.4 & 0.2 & 0.03 \\
\hline Total & $\mathbf{2 7 . 4}$ & $\mathbf{1 9 . 1}$ & $\mathbf{1 2 . 4}$ \\
\hline
\end{tabular}

Simulation studies were conducted with groups of $n=10$, $\mathrm{n}=25$ and $\mathrm{n}=50$ asynchronous cells with normally distributed switching periods with a mean of $100 \mu \mathrm{S}$ and with a standard deviation of $5 \mu \mathrm{S}$. The input voltage to each converter was $2 \mathrm{~V}$ and the duty ratio was set at $50 \%$, the maximum distortion voltage case.

Table II compares expected distortion voltages against those predicted by Equation 1. For 50 converters, the typical output waveform of the group, without an inductor, is shown as Figure 4. In this case a distortion voltage of 7 Vrms at $10 \mathrm{kHz}$ remains at the output of the group and this can be further reduced by a single common filtering inductor.

A non-distributed approach produces a $10 \mathrm{kHz}$ square wave of $50 \mathrm{~V}$ average and $100 \mathrm{~V}$ peak magnitude, that is a distortion component of $50 \mathrm{Vrms}$ so substantial cancellation has been achieved. A characteristic of this approach is the presence of amplitude or envelope beat frequencies related to the spread of the DC to DC converter switching frequencies.

\section{MPPT WITHOUT A CURRENT SENSOR}

Considering that many converters - tens up to hundreds of converters - are connected in series the voltage change forced by one cell generates only a minor variation in the load current. If the load current for each DC/DC converter can be assumed as a constant then output power of each individual converter is proportional to its output voltage. The MPPT function can be achieved by sensing and maximizing the output voltage. This approach is valid for any case where an increase in converter output voltage produces a monotonic, but not necessarily proportional, increase in load power.

As indicated in Figure 5 the output voltage can be determined from the cell voltage and the converter duty cycle. A simple perturb and observe scheme is employed to track the peak power. In order to achieve fast dynamics, a variable step size is used, as shown in (3).

$$
D_{k+1}^{*}=D_{k}^{*}+M \cdot \frac{\Delta P_{k}}{\Delta V_{k}}
$$

In this instance the Perturb and Observe controller, [8-9], makes variations in converter duty cycle and the observed corresponding output power changes are used to determine the direction of future duty cycle adjustments.

TABLE II.

DISTORTION VOLTAGES

\begin{tabular}{|c|c|c|c|}
\hline $\mathrm{N}$ & $\begin{array}{c}\text { DC } \\
\text { Output } \\
(\mathrm{V})\end{array}$ & $\begin{array}{c}\text { Expected } \\
\text { Distortion } \\
(\mathrm{V})\end{array}$ & $\begin{array}{c}\text { Measured } \\
\text { Distortion (V) }\end{array}$ \\
\hline 1 & 1 & $1.00(100 \%)$ & 1.00 \\
\hline 10 & 10 & $3.16(31 \%)$ & 3.16 \\
\hline 25 & 25 & $5.00(20 \%)$ & 4.82 \\
\hline 50 & 50 & $7.07(14 \%)$ & 6.99 \\
\hline
\end{tabular}

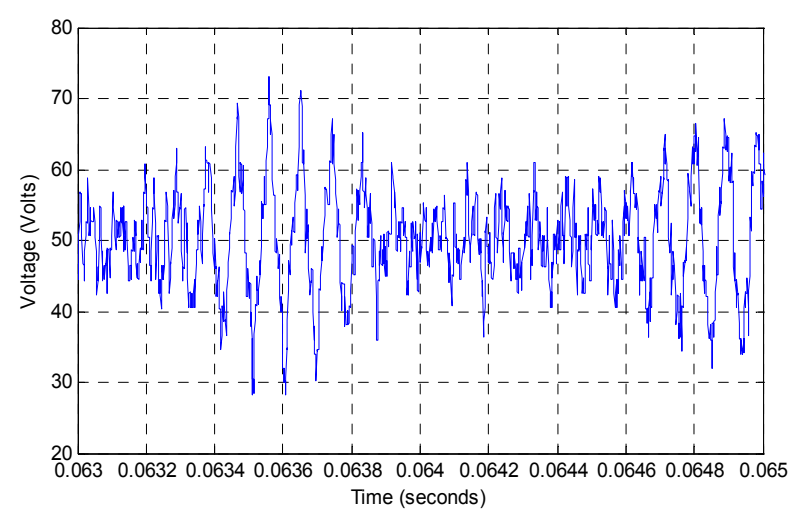

Figure 4: Typical output voltage waveform of group of 50 cells.

This scheme has been modeled in MATLAB/SIMULINK environment. A buck converter running at $20 \mathrm{kHz}$ is employed. Figure 6 shows the dynamics of cell voltage, cell current, output power and duty cycle of the converter during illumination level, load current and temperature variations. Under this scheme, same maximum power can be achieved as the MPPT using actual power inferred from current and voltage measurements. It is seen that when the illumination level changes from 600 to $1000 \mathrm{~W} / \mathrm{m}^{2}$, the duty ratio changes quickly to pick up the new peak power. At $0.1 \mathrm{~s}$, the illumination reduces to $800 \mathrm{~W} / \mathrm{m}^{2}$. The proposed scheme 


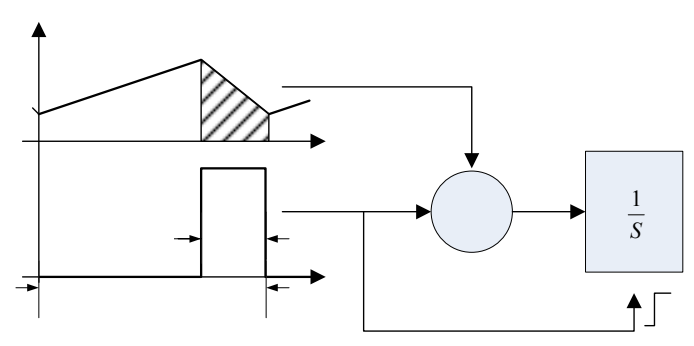

Figure 5: Calculation of power without the current.
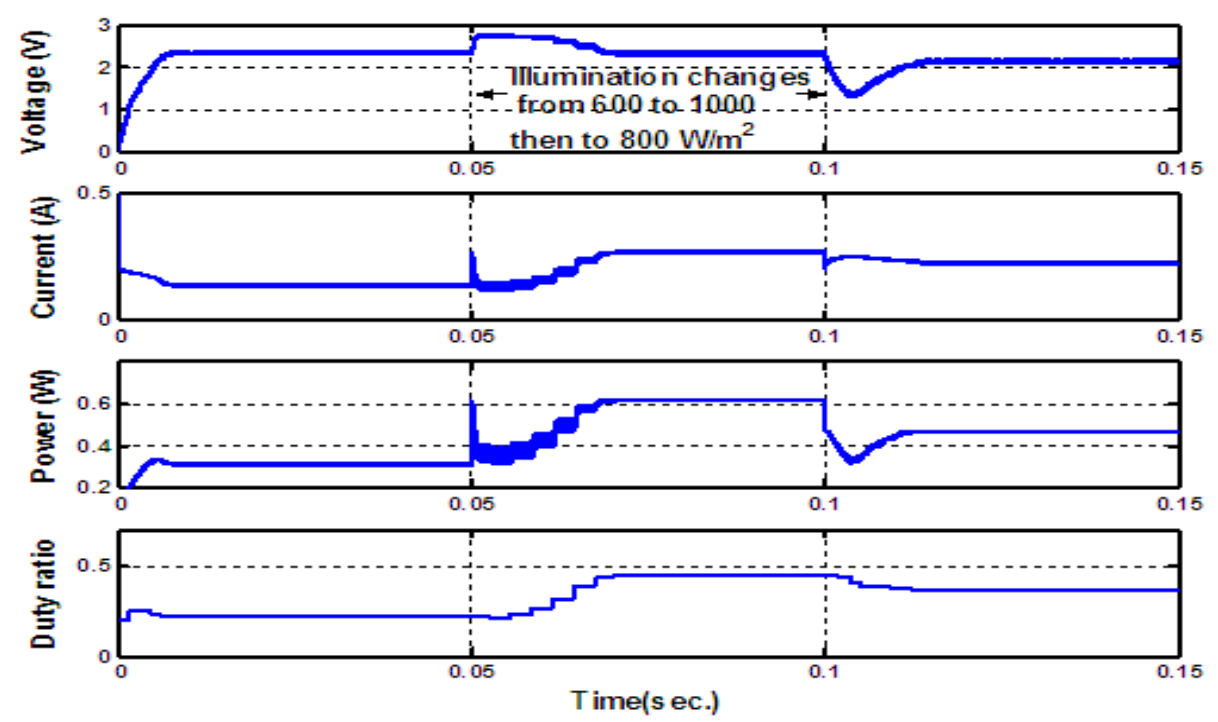

Figure 6: Dynamic response of the proposed MPPT scheme based on voltage.

tracks the output power accurately and with very short time delay without current sensor which is normally required for other MPPT schemes.

\section{EXPERIMENTAL RESULTS}

A prototype converter was developed to first examine the conversion efficiency of the DC to DC converter stage. For these tests the MSP340 was programmed to drive the charge pump circuitry and to operate the buck converter stage at a fixed 50\% duty ratio. A header board with a MSP 430F 1232 is used as the controller as shown in Figure 7. A fixed $2 \mathrm{~V}$ input source voltage was applied and a load consisting of a $2500 \mu \mathrm{H}$ inductor and a $1.6 \Omega$ resistor is employed. A deadtime of $0.8 \mu \mathrm{S}$ is inserted in each turn-on and turn-off transient to prevent MOSFETs shoot through conduction events.

Figure 8 shows the loaded waveforms. Note the conduction of the MOSFET inverse diodes in the dead time which generates $2 \mu \mathrm{S}$ wide peaks on the leading and trailing pulse top edges on the top trace. The transfer of current to these diodes which have a much higher forward drop than the MOSFET channel generates an additional conduction loss of $14 \mathrm{~mW}$ which reduces efficiency at higher frequencies.

Efficiency is a key parameter that is difficult to gauge using input-output power measurements. Given circuit losses are around a few percentage points of rating, precise voltage and current measurements are needed. A complication is that the output is inductorless and both the output voltage and current contain significant switching frequency components. It is possible, in fact likely, that a significant amount of power is transferred to the combined R-L load at frequencies other than DC.

In order to determine the efficiency of this converter, a new high end oscilloscope was used to measure the input and output power. The internal math function was employed to obtain the instantaneous power from the current and voltage, the mean value of which indicates the average power. The current probes were carefully calibrated before each current measurement, to minimize measurement errors. The efficiency of the converter at different switching frequency can be shown in Table III.

The results do confirm that the circuit is capable of achieving high efficiencies especially if the switching frequency is low. The loss during dead-time is the main contributor for total loss. To improve the efficiency, a faster 
comparator has been used to reduce the dead-time as small as $0.2 \sim 0.4 \mu \mathrm{s}$.

The efficiency of the converter at $50 \%$ duty cycle and 20 $\mathrm{kHz}$ switching frequency was additionally confirmed by a calorimeter based efficiency measurement at 98\%. A converter was placed in a thermos flask immersed in transformer oil. This in turn was placed in an environmentally controlled cabinet with a temperature accuracy of $0.3^{\circ} \mathrm{C}$. A Wheatstone bridge of four platinum PT 100 resistance probes, followed by an instrumentation amplifier with a gain of 1000 , was used to measure the steady state temperature rise within the flask above the environment after several hours. The flask had been previously characterized for temperature rise using a number of resistor loads with known powers in the range of $1 \mathrm{~mW}$ to $50 \mathrm{~mW}$ placed in the oil bath. A linear regression line was fitted through the experimental points from the known loads. This method resulted in an experimental error below $2 \mathrm{~mW}$.

The maximum power tracking speed response of the new converter was demonstrated with an analogue component model of a solar cell using a switchable current source to represent the solar cell optical current. This was shunted by three series connected silicon diodes which progressively diverted the model optical current at voltages above approximately $2 \mathrm{~V}$. The simulator can switch between simulated optical currents of $150 \mathrm{~mA}$ and $300 \mathrm{~mA}$. The $i-v$ characteristic and power curves for the simulator are shown in Figure 9.

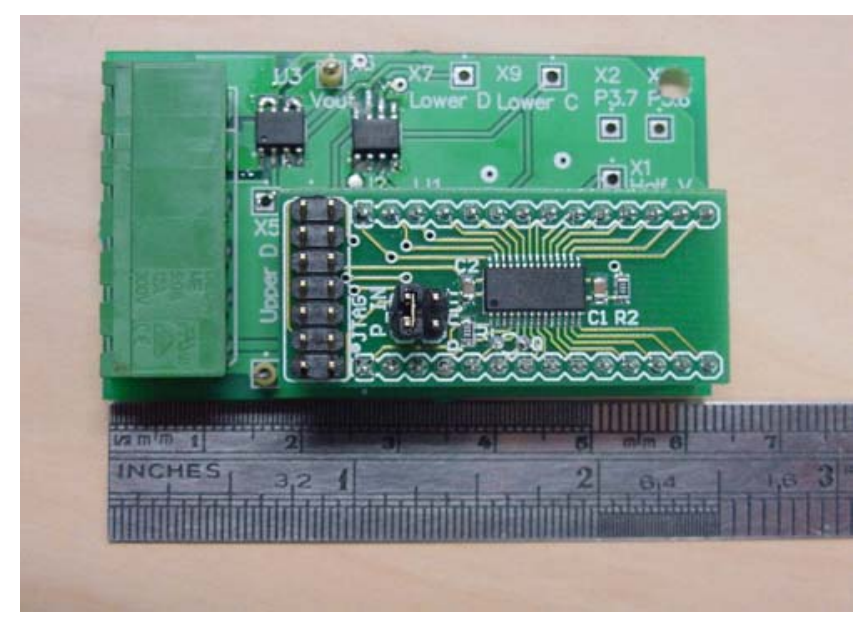

Figure 7: Experimental Converter

TABLE III.

EFFICIENCY AT DIFFERENT SWITCHING FREQUENCIES.

\begin{tabular}{|c|c|c|c|}
\hline $\begin{array}{c}\text { Frequency } \\
(\mathrm{kHz})\end{array}$ & $\begin{array}{c}\text { Input } \\
\text { Power } \\
(\mathrm{mW})\end{array}$ & $\begin{array}{c}\text { Output } \\
\text { Power }(\mathrm{mW})\end{array}$ & Efficiency \\
\hline 2 & 520 & 510 & $98 \%$ \\
\hline 10 & 577 & 547 & $95 \%$ \\
\hline 20 & 506 & 471 & $93 \%$ \\
\hline
\end{tabular}

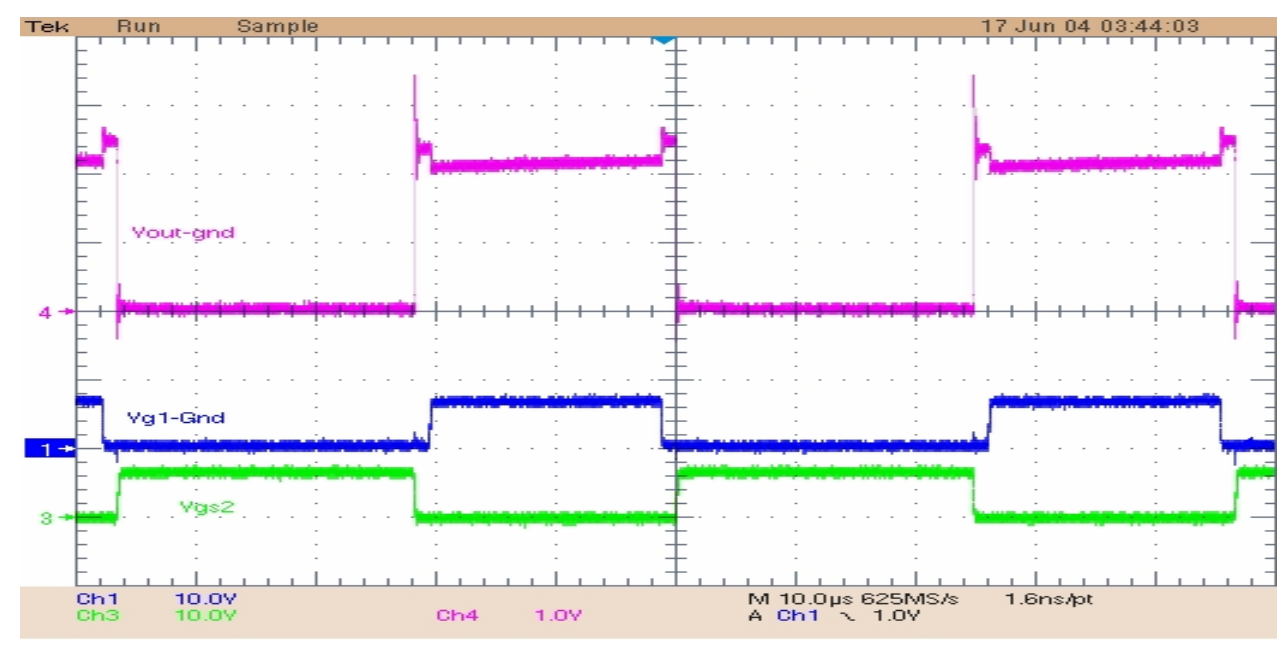

Figure 8: Loaded $20 \mathrm{kHz}$ Waveforms, Traces top to bottom, output terminal, bottom MOSFET gate, top MOSFET gate, all referred to ground.

A significant advantage of the analogue simulator is that an extremely rapid change in the simulated illumination level is produced. The current source will switch in a few microseconds and this is negligible in comparison to maximum power tracker response time. The analogue model appears to be a very usable alternative to solar simulators based on controllable lamps, [9], especially in regard to the evaluation of very rapid illumination changes.
The analogue simulator will not however reproduce the solar cell thermal responses. Some experimental difficulty was experienced with existing converter with directly illuminated dual junction cells. These could drop their maximum power voltage to below $1.8 \mathrm{~V}$ at cell temperatures above $60^{\circ} \mathrm{C}$ which caused resetting of the MSP340. This is not a problem with triple junction cells. This issue can be addressed by applying a charge pump solution to the supply 
of the MSP340 and this would extend the converter application down to $0.8 \mathrm{~V}$.

One important modification to the Perturb and Observe algorithm simulated earlier is made to ease the implementation issues on the MSP340 device. The simulated algorithm made perturbations to converter duty cycle and observed the effects on output average voltage. The practical algorithm is implemented using an "interior voltage loop". The cell voltage is controlled by a regulatory control loop which accepts cell voltage set points from the maximum power tracking system. The converter average output voltage is calculated using the cell set point voltage and the converter duty cycle which is now determined by the voltage regulation loop. The perturb and observe system now makes variations in cell set point voltage so as to maximize the converter output voltage and hence power.

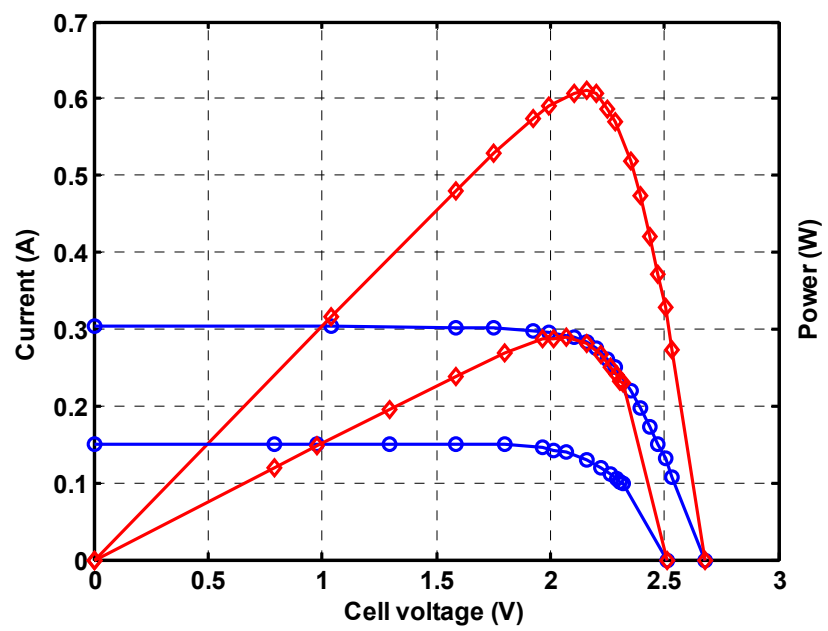

Figure 9: The $i-v$ and $p-v$ characteristics of the solar cell simulator measured characteristics.
A key feature of this approach is a very rapid response to illumination changes. The interior voltage loop responds in a few converter switching cycles to maintain the cell voltage. As seen in Figure 9 the major immediate effect of the illumination change is a change in cell current and the maximum power point voltage shift is relatively small. The corresponding duty cycle change required to maintain the cell voltage is much larger.

The Perturb and Observe system is capable of responding to the small residual adjustments in peak power voltage due to illumination over time. It will also respond to variations in cell temperature which impact more strongly, but rather slowly, on the maximum power point voltage.

Figures 10 and 11 show the response of the converter for step changes in illumination. The cell voltage waveform is at the mid point of the divider formed by $R_{1}$ and $R_{2}, 1 \mathrm{~V}$ at this point corresponds to a cell voltage of $2 \mathrm{~V}$. Due to the limit on ADC conversion times of the MSP340 a single observation of cell voltage is made each switching cycle.

The step up response in Figure 10 shows a rapid increase in cell current which begins to elevate the converter input capacitor voltage. As the voltage rises beyond the maximum power point the cell current falls until the voltage regulator loop responds by increasing the converter duty cycle. The voltage regulator response is effectively complete within $1.5 \mathrm{mS}$ or twenty converter switching cycles. The Perturb and Observe method runs at a lower rate with perturbations being made every eight converter cycles. While the voltage loop response has not completely settled in eight cycles the experimental work indicates that enough of the system response is observable to produce the correct decisions for the next perturbation step. A higher speed response could be achieved for the MPPT by making the next perturbation once the response direction was clear.

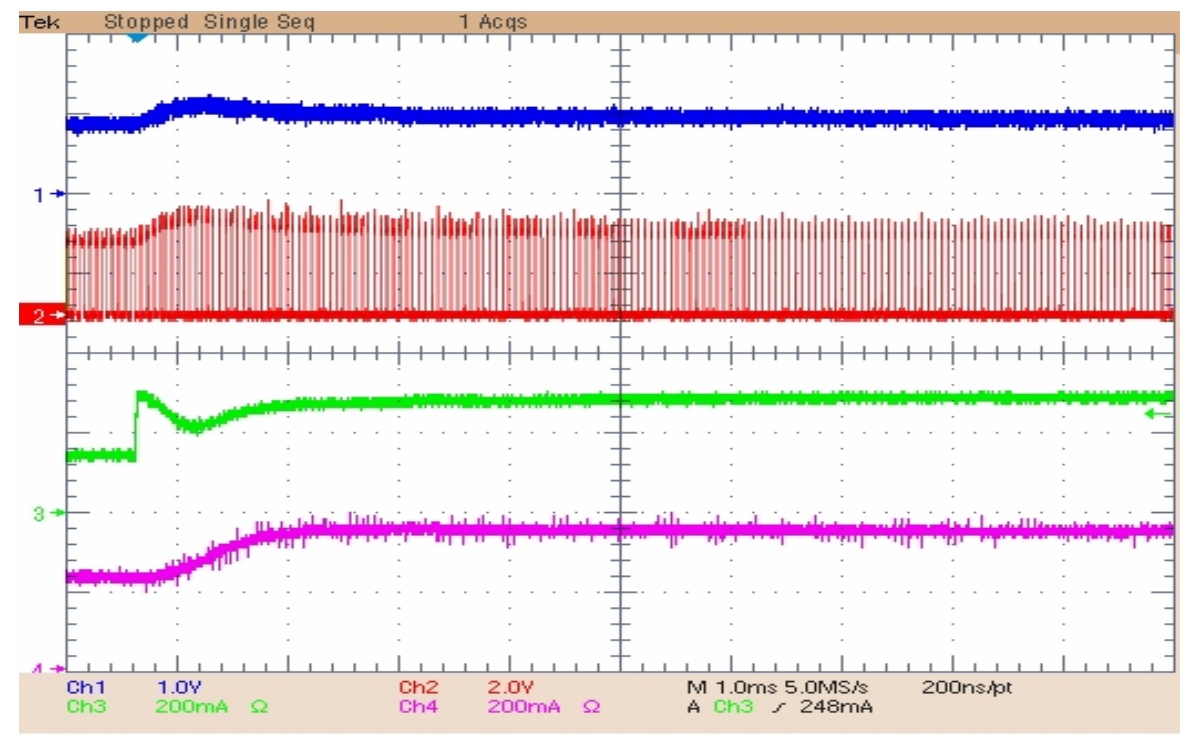

Figure 10: Illumination step-up dynamics, from top to bottom, cell voltage, middle point referred to ground, cell current and load current. 


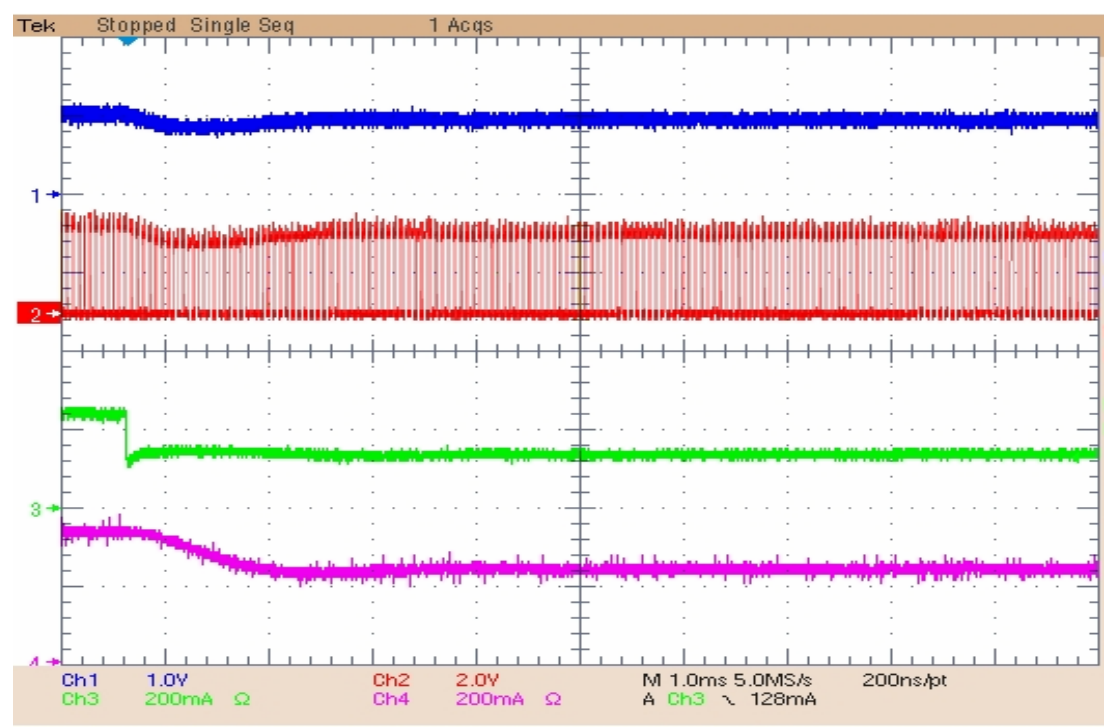

Figure 11: Illumination step-down response, from top to bottom, cell voltage, middle point to ground, cell current and load current.

Figure 11 shows the corresponding response for a step down in illumination. In this case the cell current immediately falls and the converter capacitor voltage moves below the maximum power point until the voltage loop response reduces the output current. Again this response is largely complete in $1.5 \mathrm{mS}$ and the Perturb and Observe method then moves to slowly adjust the voltage set point to allow for a small variation in maximum power voltage.

\section{CONCLUSION}

A distributed converter and MPPT scheme for vehicle solar arrays was proposed and investigated. The results show a high efficiency converter suited to single cell operations is possible even for converter ratings below one watt. The efficiency of the converter was measured as being as high as $98 \%$ at $2 \mathrm{kHz}$ by using oscilloscope and its math functions and was verified by calorimeter method.

A maximum power tracking method that required only measurements of the cell voltage was demonstrated using an analogue solar cell simulator that is capable of simulating very rapid illumination changes. The benefits of using an interior voltage loop for the compensation for changes in illumination was demonstrated. An interior loop provides a rapid initial response to illumination changes with major effects being compensated within $1.5 \mathrm{mS}$. The residual effects of illumination changes can be fine tuned by a higher level Perturb and Observe optimization method which is also effective in tracking temperature induced changes to the maximum power point.

\section{ACKNOWLEDGMENT}

This work was supported by the Queensland Department of Public Works and Housing and the Queensland Department of Transport.

\section{REFERENCES}

[1] J. Voelcker, "Top 10 Tech Cars, Here Come the Hybrids", IEEE Spectrum, March 2004, pp 20-27.

[2] A. Simpson, G. Walker, M. Greaves, D. Finn, B. Guymer, "The Ultra Commuter: A Viable and Desirable Solar Powered Commuter. Vehicle", Australian Universities Power Engineering Conference, AUPEC 2002, University of Monash, Melbourne, Australia, $29^{\text {th }}$ September $-2^{\text {nd }}$ October 2002. Available:

http://www.itee.uq.edu.au/ aupec/ .

[3] Spectrolab Inc Sylmar California. 28.0\% Ultra triple Junction (UJT) Solar Cells. Available:

http://www.spectrolab.com/DataSheets/TNJCell/utj.pdf

[4] Spectrolab Inc Sylmar California. GaInP $2 / \mathrm{GaAs} / \mathrm{Ge}$ Dual Triple Junction Solar Cells. Available: http://www.spectrolab.com/DataSheets/DJCell/dj.pdf

[5] J. H. R Enslin, M. S. Wolf, D. B. Snyman, W. Sweighers, "Integrated Maximum Power Point Tracking Converter", IEEE Transactions on Industrial Electronics, Vol 44, No.6 December 1997, pp 343-349.

[6] G. R. Walker, J. Xue, P. Sernia, "PV String Per-Module Maximum Power Point Enabling Convertrers", Australian Universities Power Engineering Conference, AUPEC 2003, University of Canterbury, Christchurch, New Zealand, $28^{\text {th }}$ September - $1^{\text {st }}$ October 2003. Available: http://www.itee.uq.edu.au/ aupec/.

[7] J. Steger, R. Roehrig, "Process and Circuit to Control and Regulated a Photovoltaic Device Assembly for Solar Energy has Controlled Current Bypass for each Cell to ensure Maximum Power Operation", European Patent DE10222621, $27^{\text {th }}$ November 2003.

[8] K. H. Hussein, I. Muta, T. Hoshino, M. Osakada, "Maximum Photovoltaic Power Tracking: an Algorithm for Rapidly Changing Atmospheric Conditions", Proceedings IEE G, vol 142, January 1995, pp 59-64.

[9] D. P. Hohm, M. E. Ropp, "Comparative Study of Maximum Power Point Tracking Algorithms using an Experimental, Programmable, Maximum Power Point Tracking Test Bed", Conference Record of the Twenty-Eighth IEEE Photovoltaic Specialists Conference, 2000, pp $1699-1702$. 